Ingeniare. Revista chilena de ingeniería, vol. $14 \mathrm{~N}^{\circ} 3,2006$, pp. 187-202

\title{
EVALUACIÓN DE LA EFECTIVIDAD DE LA BANCA CHILENA EN INTERNET PARA LA GENERACIÓN DE ESTRATEGIAS DE NEGOCIOS BANCARIOS EN LA WEB
}

\section{EVALUATION OF THE EFFECTIVENESS OF INTERNET BANKING IN CHILE FOR THE GENERATION OF WEB-BASED BANKING BUSINESSES STRATEGIES}

\author{
Fabián Vergara $^{1} \quad$ Narciso Cerpa $^{1} \quad$ Rodrigo Loyola $^{1} \quad$ Per Bjarne Bro $^{1}$ \\ Recibido 29 de agosto de 2005, aceptado el 23 de agosto de 2006 \\ Received: August 29, 2005 Accepted: August 23, 2006
}

\begin{abstract}
RESUMEN
Este estudio tiene como objetivo principal analizar la efectividad de los servicios bancarios a través de Internet en Chile provistos por trece bancos nacionales. Para ello se consideraron dos etapas, la primera correspondió a la evaluación de funcionalidades de los sitios Web bancarios, utilizando una adaptación del modelo de evaluación de sitios Web de Hersey, y la segunda a la evaluación de los servicios según las percepciones de los clientes. Para la determinación de las funcionalidades fue necesario detectar la presencia o ausencia de treinta y siete elementos evaluados, según lo cual fue posible clasificar al sector bancario chileno en términos de lo que ofrece o no cada institución. Por otra parte, la encuesta aplicada tanto a usuarios como no usuarios de la banca en línea permitió conocer variados factores referentes al uso y no uso de los servicios. A pesar de que existen algunos aspectos en los que la banca nacional se desempeña sólo de forma regular, en el contexto global lo hace con un alto grado de efectividad. Además, el buen desempeño en el contexto general se hace evidente al observar la gran equiparidad existente entre los resultados nacionales y los de la banca neocelandesa

Palabras clave: Banca en Internet, modelo de evaluación de sitios web, modelo Hersey, banca chilena, banca electrónica, banca en línea, servicios financieros en Internet.

ABSTRACT

The main objective of this study is to analyze the effectiveness of the services of Internet banking provided by thirteen Chilean banking institutions. To achieve this objective, two stages were considered. The first stage corresponded to the evaluation of the functionalities offered by the banking Web sites, using an adaptation of the Hersey Web site evaluation model. The second stage corresponded to the evaluation of the services according to the clients' perceptions. In order to determine the functionalities offered by banking Web sites it was necessary to detect the presence or absence of thirty seven elements. This approach permitted to rank the Chilean banking sector based on the Internet offer of each institution. On the other hand, the survey applied to non-users as well as users of Internet banking, allowed us to find a variety of factors that encourage or inhibit the use of the banking services. Although there are some aspects in which the Chilean banking industry has an average performance, in general, it is highly effective. In addition, good productivity in the global context becomes evident when observing the similarity between the results in Chile and those of the New Zealand's banking institutions.
\end{abstract}

Keywords: Internet banking, web site evaluation model, Hersey model, e-banking, chilean banks, on line banking, financial services on Internet.

\section{INTRODUCCIÓN}

Hoy en día la sociedad enfrenta constantemente mayores demandas por servicios durante las 24 horas del día. Esta tendencia se ha intensificado en la actualidad, época en la que muchas personas han debido hacer frente a la escasez de tiempo, ante lo cual dichos servicios se han vuelto muy valorados.

Frente a la escasez de tiempo, han surgido innovaciones tecnológicas que apoyan y estimulan la implementación de ellos, haciendo inminente el advenimiento de la era

\footnotetext{
1 Facultad de Ingeniería, Universidad de Talca. Merced 437, Curicó, Chile, email: favergara@utalca.cl, ncerpa@utalca.cl, rloyola@utalca.cl, pbro@utalca.cl
} 
de la computación omnipresente donde todo el mundo está conectado [1]. Entre estas innovaciones destaca notablemente la introducción y desarrollo de los servicios bancarios a través de Internet.

Considerando los cambios sociales y tecnológicos mencionados, en nuestro país catorce instituciones bancarias están entregando en la actualidad diversos servicios que permiten a sus clientes realizar un amplio rango de trámites las 24 horas del día al margen del lugar en que se encuentren.

La comunidad bancaria históricamente ha competido por el camino tradicional de ofrecer servicios convencionales. Actualmente, en una búsqueda por adaptarse rápidamente a los cambios, ha traspasado la competencia a la Web, a través de la banca por Internet, ofreciendo a sus clientes servicios a través de este medio con una amplia visión de futuro [2]. Dado lo anterior, es claro que Internet puede hacer que los bancos comerciales den nuevos e inesperados saltos en sus organizaciones generando equilibrio en sus servicios [3].

Con los actuales niveles de penetración de Internet se ha logrado entregar a los bancos una nueva herramienta, en términos estratégicos, económicos y competitivos. En vista de que los cambios tecnológicos están siendo cada vez más aceptados y la alfabetización digital sigue creciendo, Internet se ha convertido en una herramienta potente para los bancos [4]. A modo de ejemplo, mientras las instituciones financieras australianas han sido lentas en la aceptación de Internet en el sector, se ha observado que casi todos los bancos y otros establecimientos financieros ofrecen los medios bancarios en línea o están planeando hacerlo en un futuro cercano [5]. De acuerdo a las fuentes consultadas, en la actualidad se estima que una transacción bancaria en la sucursal cuesta alrededor de US $\$ 1,07$; vía telefónica, cerca de los US $\$ 0,35$; a través de un ATM US $\$ 0,27$ y vía Internet, la suma desciende a US\$ 0,01 [6]. Según estudios de la Cámara de Comercio de Santiago [7] en Chile una transacción bancaria vía Internet cuesta alrededor de un $10 \%$ de su equivalente físico en la sucursal.

Dentro de la industria financiera mundial, al igual que en Chile, son los grandes bancos (no necesariamente los pioneros) los que han tenido un mayor éxito en el desarrollo de plataformas de la banca por Internet. Esto se debe fundamentalmente a tres factores [8]:

1. Cuentan con grandes bases de clientes, fieles y estables (poco propensos al cambio).
2. Cuentan con identidad de marca y son altamente reconocidas en el mercado, lo que se traduce en seguridad para los clientes.

3. Tienen la posibilidad de ofrecer a sus clientes acceso a sus cuentas e inversiones a través de múltiples canales, permitiéndoles mayor autonomía en la organización de sus finanzas.

Como se desprende de lo expuesto en los párrafos anteriores, este estudio explorará los servicios de la banca en línea para personas en Chile y las estrategias como los bancos pueden mejorar sus servicios en Internet. De las catorce instituciones antes señaladas se trabajó con las trece que explicitan sus servicios sin necesidad de claves de acceso, estos bancos serán evaluados en términos de la efectividad y funcionalidad de sus servicios en la Web. La funcionalidad será examinada a través de la evaluación de los sitios Web usando el modelo de comercio electrónico de Hersey (1996) adaptado al ambiente bancario, mientras que la efectividad se estudiará a través de una encuesta aplicada a una muestra adecuada de clientes reales y potenciales de los servicios en línea.

En la actualidad la banca chilena en Internet se encuentra en un puesto privilegiado dentro del ámbito latino, por lo cual se considera necesario comenzar a comparar con países que en el concierto mundial se encuentran en posiciones primarias. Para esto, los aspectos más importantes de este estudio se contrastarán con resultados provenientes de la banca neocelandesa.

Los resultados de este estudio proveerán información para que los bancos mejoren sus servicios y estrategias de negocios en Internet. Además, entregarán datos que pueden ser considerados por las instituciones para atraer nuevos usuarios y a aumentar la retención.

\section{DEMANDA DE LA BANCA POR INTERNET EN CHILE}

El número de internautas que posee cuentas bancarias en Chile se estima en aproximadamente un millón cuatrocientas mil personas, lo cual, considerando que el nivel de penetración de Internet en Chile alcanza al 36\% [9], equivale a aproximadamente a un $26 \%$ de la población con acceso a Internet. Estos niveles de penetración son elevados en comparación a los países latinoamericanos e incluso igualan a los de algunos países desarrollados como España e Italia [9].

Como se puede ver en la figura 1, elaborada en el año 2002, para los países desarrollados y líderes en la inserción de 
tecnologías de información se proyectaba una penetración de alrededor del 75\% y 95\% para los años 2005 y 2010 respectivamente, mientras que para los países desarrollados con menores tasas de inserción del servicio se intuía una penetración máxima de un 50\% y $90 \%$ para los mismos años. Por otro lado, para las economías emergentes las proyecciones indicaban niveles de inserción del 18\% y $67 \%$ para los años 2005 y 2010. De acuerdo a cifras publicadas por la Superintendencia de Bancos de Chile [11] a fines de 2002 existían 687 mil clientes con acceso a la banca a través de Internet, sobre un total de 1,25 millones de cuentas corrientes, es decir, $54 \%$ de penetración, mientras que para el año 2004 existían 870 mil clientes Internet, sobre un total de 1,4 millones de cuentas corrientes, es decir, $62 \%$ de penetración.

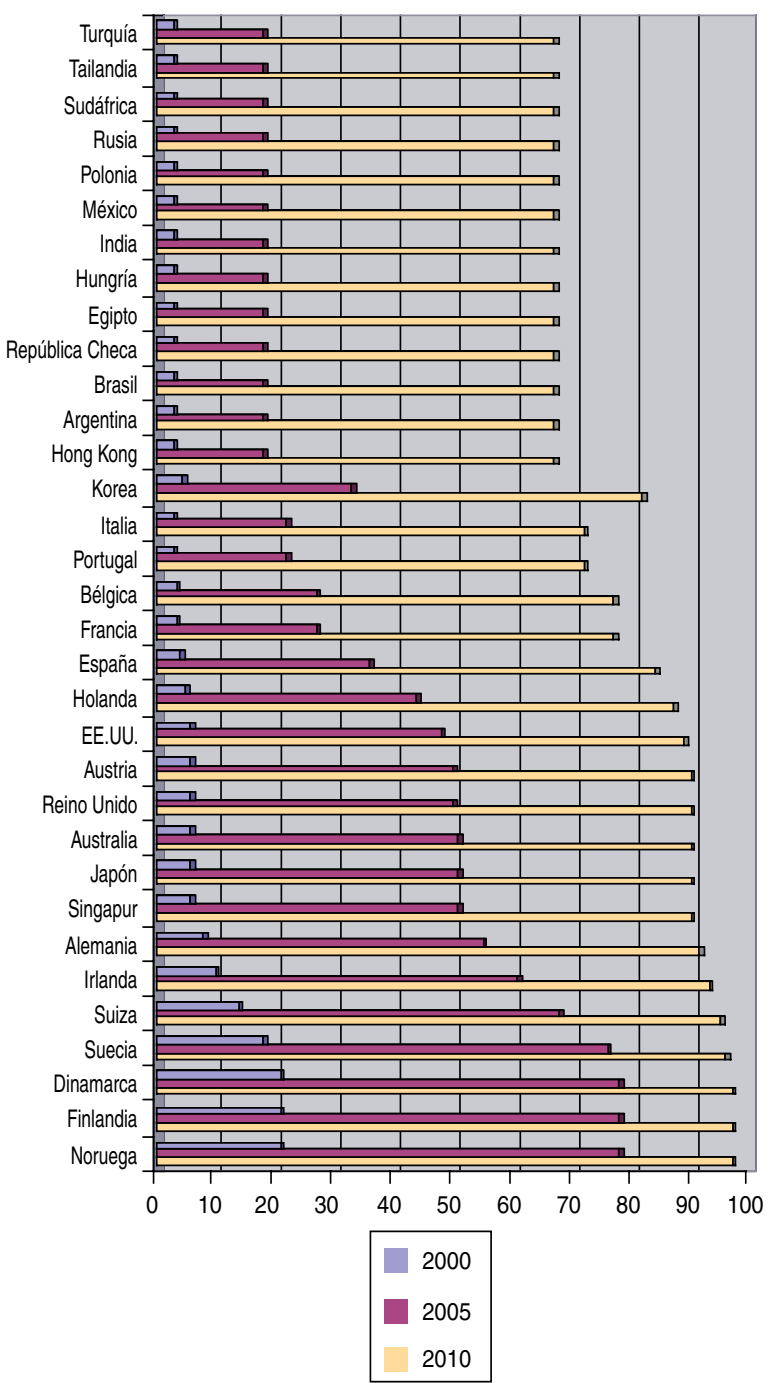

Figura 1. Penetración de E-banking: tasas reales y proyectadas para 2000, 2005 y 2010 [10].
A nivel transaccional la penetración también ha sido rápida. En diciembre de 2000, las transferencias de fondos a través de Internet fueron el equivalente al 3\% de los cheques emitidos físicamente [8].

\section{MODELO GENERAL DE HERSEY PARA LA EVALUACIÓN DE SITIOS WEB}

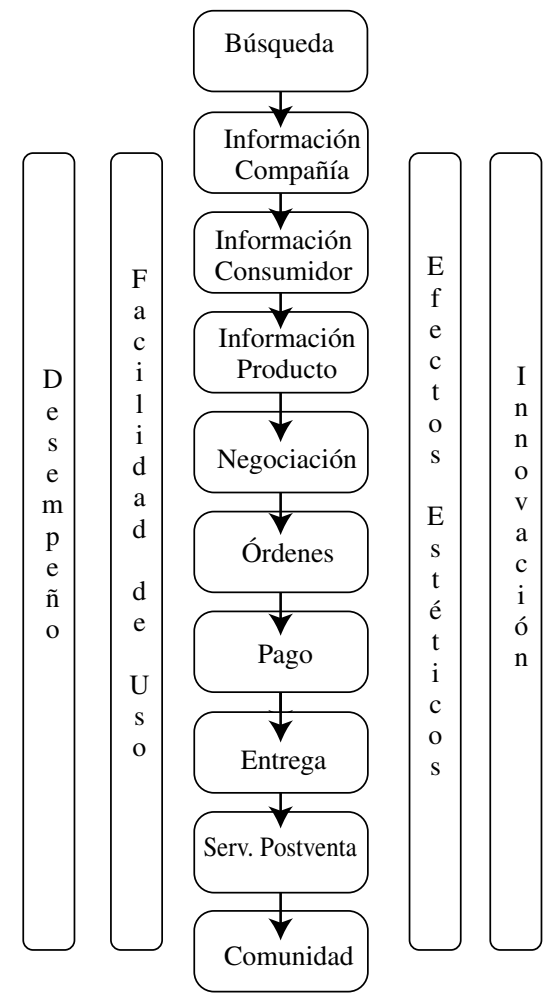

Figura 2. Modelo General de Hersey.

El Modelo General de Hersey [12] para la evaluación de sitios Web, figura 2, separa la interacción usuario remoto-sitio Web en una serie de categorías:

- Información de la Compañía

- Información del Consumidor

- Información del Producto

- Negociación

- Órdenes

- Pago

- Entrega del Producto

- Servicio Postventa

- Desarrollo de la Comunidad 
y cuatro categorías que están presentes en todos los pasos mencionados anteriormente:

- Desempeño (Performance)

- Facilidad de Uso

- Efectos Estéticos

- Innovación

La categoría desempeño tiene un mayor énfasis al comienzo y al final del proceso de interacción, mientras que la Facilidad de Uso es más relevante en las etapas intermedias. La estética e innovación están presentes en todas las etapas de la interacción.

La categoría Negociación hace referencia a la posibilidad de obtener precios de productos, disponibilidad y condiciones de venta. La entrega hace referencia a la posibilidad de especificar los procedimientos y mecanismos para la entrega del producto. La categoría Desarrollo de la Comunidad es la funcionalidad que un sitio Web puede proveer para reunir retroalimentación de parte de los clientes y para permitirles compartir información entre ellos.

\section{ADAPTACIÓN DEL MODELO DE HERSEY}

Los sitios Web de los bancos son especiales, debido a que generan una relación diferente con los clientes si se compara con el nexo que se tiene a través de los servicios convencionales, por medio de los cuales suele generarse una relación de más largo plazo. Para un cliente tradicional, cambiarse de un banco a otro es una decisión importante, mientras que los compradores en línea demuestran menos lealtad a los abastecedores específicos de otros productos o servicios, ya que para ellos el cambio está sólo a un clic de distancia. Debido a los requerimientos específicos presentados por la banca, tales como seguridad, privacidad, integridad de los datos, desempeño, etc., es que sus sitios deben estar cuidadosamente diseñados para satisfacer estas necesidades, por tanto, un modelo de evaluación de sitios Web bancarios debe considerar estos factores.

En el modelo adaptado de Hersey $[14,15]$ las categorías "Información de la compañía", "Información del consumidor" e "Información de producto" fueron incluidas en una categoría general llamada "Información". Las categorías "Ordenes", "Pago", "Entrega" y "Post-Venta" fueron incluidas en una categoría denominada "Orden". La "Facilidad de uso" fue ampliada para incluir los siguientes elementos: Preguntas frecuentes, servicio de demostración, servicio de búsqueda, funciones de ayuda y botones o menú de navegación. Debido a que la declaración de legalidad para las transacciones y las políticas de privacidad son particularmente importantes para las instituciones financieras, una categoría denominada "Estado Legal" fue agregada al modelo de Hersey para cubrir estos conceptos por Paynter y Chung [14, 15].

Tabla 1. Categorías y elementos a evaluar en los sitios web bancarios chilenos.

\begin{tabular}{|c|c|}
\hline Categoría & Elemento \\
\hline \multirow{4}{*}{ Información } & Información de la compañía \\
\hline & Información del consumidor \\
\hline & Información financiera \\
\hline & Información del producto \\
\hline \multirow{2}{*}{$\begin{array}{l}\text { Estado } \\
\text { Legal }\end{array}$} & Póliza de privacidad (explícita) \\
\hline & Póliza de seguridad (explícita) \\
\hline \multirow{11}{*}{ Uso } & Balance de cuentas (saldos) \\
\hline & $\begin{array}{l}\text { Transferencia de fondos entre cuentas del } \\
\text { mismo usuario en el mismo banco }\end{array}$ \\
\hline & $\begin{array}{l}\text { Transferencia de fondos a terceros del } \\
\text { mismo banco }\end{array}$ \\
\hline & $\begin{array}{l}\text { Transferencia de fondos a cuentas de otro } \\
\text { banco }\end{array}$ \\
\hline & Cartola de movimientos \\
\hline & Compra de productos del banco \\
\hline & Bajar información de cuentas a un software \\
\hline & Hacer pagos de cuentas \\
\hline & Ordenar talonario de cheques \\
\hline & Cambiar clave \\
\hline & Servicio postventa \\
\hline \multirow{6}{*}{$\begin{array}{l}\text { Facilidad } \\
\text { de Uso }\end{array}$} & Preguntas frecuentes \\
\hline & Servicio de demostración \\
\hline & Servicio de búsqueda \\
\hline & Ayuda \\
\hline & Navegación \\
\hline & Servicio para discapacitados \\
\hline \multirow{3}{*}{$\begin{array}{l}\text { Efectos } \\
\text { Estéticos y } \\
\text { Audio }\end{array}$} & Gráfica \\
\hline & Animaciones \\
\hline & Audio \\
\hline \multirow{3}{*}{$\begin{array}{l}\text { Promoción } \\
\text { (Comercio } \\
\text { Electrónico) }\end{array}$} & Compra en tiendas virtuales \\
\hline & Canje de puntos (programa de afiliación) \\
\hline & $\begin{array}{l}\text { Compra de productos en oferta especial para } \\
\text { los clientes del banco }\end{array}$ \\
\hline \multirow{3}{*}{$\begin{array}{l}\text { Valor } \\
\text { Agregado }\end{array}$} & Compra y venta de acciones \\
\hline & Seguros \\
\hline & Documentos de renta fija o fondos mutuos \\
\hline \multirow{3}{*}{ Desempeño } & Frecuencia de actualización (diaria) \\
\hline & Tiempo de respuesta (20 segundos) \\
\hline & Ausencia de problemas técnicos \\
\hline \multirow{2}{*}{ Otros } & Innovación \\
\hline & Comunidad \\
\hline
\end{tabular}


Las categorías "Innovación" y "Comunidad" fueron agrupadas en la categoría "Otros". Las categorías "Desempeño" y "Estética" se conservaron en la forma original.

En este estudio se realizó otro refinamiento del modelo adaptado de Hersey para incorporar la evaluación de los nuevos requisitos del sector bancario; para ello la categoría "Negociación" fue sacada del modelo modificado de Hersey utilizado por Chung y Paynter $[14,15]$. y se reincorporó como una sola categoría llamada "Promoción (comercio electrónico)", incluyendo elementos tales como: compra en tiendas virtuales, compra de productos en oferta especial para clientes del banco y canje de puntos. La categoría "Orden" fue renombrada como "Uso". Por otra parte, la categoría "Valor Agregado" fue incorporada en el modelo. Además, la categoría "Información" fue ampliada para incluir el elemento "Información Financiera" en la que se consideraron la publicación continua de tipos de cambios e índices financieros. El resumen de los elementos evaluados se presenta en la tabla 1 .

\section{RESULTADOS DE LA EVALUACIÓN DE LOS SITIOS WEB}

Como se puede apreciar en la figura 3, el banco B4 registra el puntaje más alto con un $86 \%$ de los elementos evaluados, seguido muy de cerca por el B2 con un $84 \%$, en el tercer lugar se encuentra el B1 con un $78 \%$. En Nueva Zelanda (NZ) (figura 4), la institución que ocupa la primera posición obtuvo un $84 \%$ (equivalente al segundo lugar chileno) [14, 15]. Por otro lado, en los últimos lugares se encuentran B7, B8 y B10 con un 59, 51 y $51 \%$ respectivamente. En NZ la última posición la ocupa una institución que cumple con un $66 \%$ de los elementos evaluados $[14,15]$.

Si se comparan las figuras 3 y 4 , puede verse que la industria bancaria neocelandesa presenta mayor homogeneidad, lo que habla claramente que en aquella nación los servicios bancarios electrónicos son más estándares. Sin embargo, y dado que en este estudio hubo algunas categorías que se sumaron a la evaluación, para poder realizar un análisis comparativo más acabado y desagregado de ambas bancas, el análisis se llevó a cabo considerando las categorías que se evaluaron en ambas naciones En este escenario es posible observar que las diferencias de desempeño bancario no producen cambios sustanciales en la posición relativa de cada banco, ya que en general las variaciones se producen entre posiciones circundantes. Sin embargo, la brecha existente entre los primeros y últimos lugares se acrecienta considerablemente. Esto se debe a que en la evaluación chilena se agregaron las categorías valor agregado y promoción (comercio electrónico).

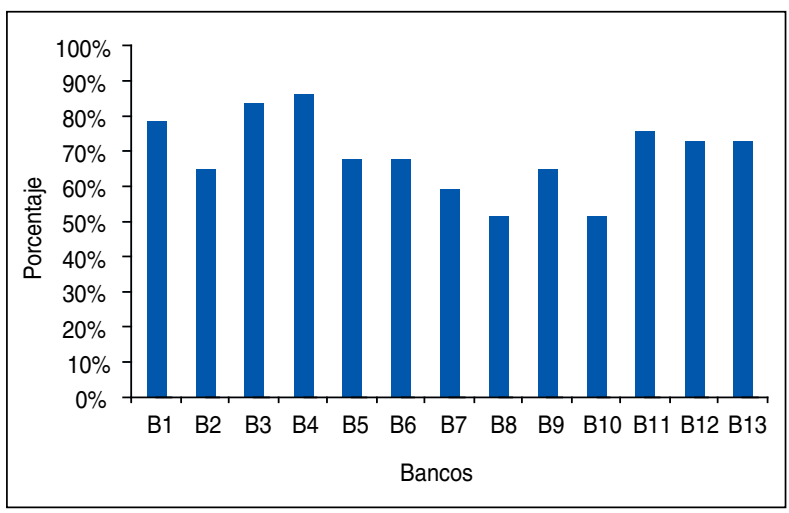

Figura 3. Evaluación de los sitios web bancarios chilenos.

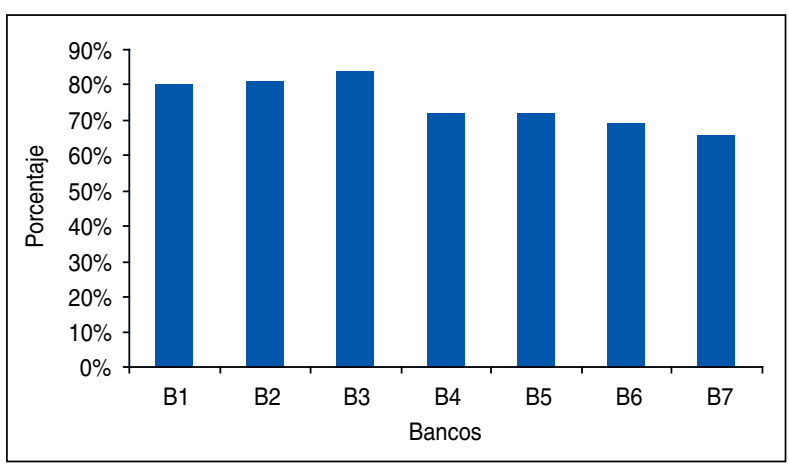

Figura 4. Evaluación de los sitios web bancarios neocelandeses $[14,15]$.

\section{Resultados de cada categoría}

Al observar la figura 5 se ve una banca homogénea en lo que respecta a información, sin embargo no presenta el grado de homogeneidad total de la banca de NZ donde la totalidad de los bancos cumple con el $100 \%$ de los elementos evaluados $[14,15]$.

En la figura 6 se observa una banca heterogénea, puesto que en el caso de la categoría estado legal tan sólo un banco $(7,6 \%)$ cumple con todos los aspectos evaluados. Este pobre desempeño de la banca nacional es atribuible a los dos aspectos considerados bajo esta categoría, pero mayoritariamente al elemento pólizas de privacidad, ya que sólo el $15 \%$ de los bancos nacionales las publica explícitamente, mientras que el 31\% lo hace para sus políticas de seguridad. En el caso de NZ, los datos consultados $[14,15]$ muestran un sector menos heterogéneo. En este caso cinco bancos $(71,5 \%)$ reúnen todos los elementos evaluados. 


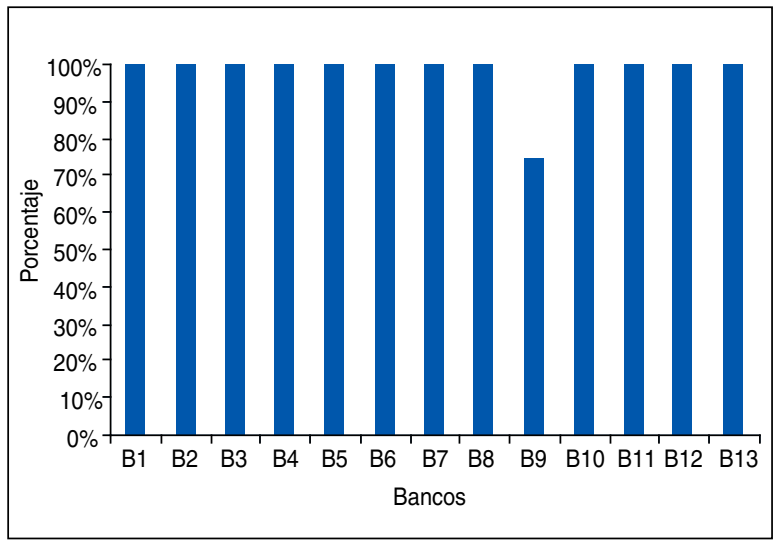

Figura 5. Desempeño de la banca chilena para la categoría de información.

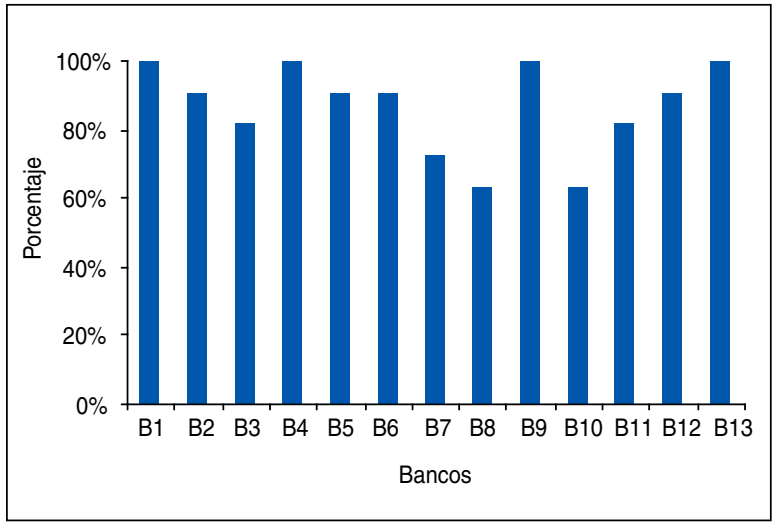

Figura 7. Desempeño de la banca chilena para la categoría uso.

En la categoría uso en la banca chilena, ver figura 7, se puede decir que está bien desarrollada ya que el $31 \%$ de los bancos cumple con el $100 \%$ de los ítems, y el $61,2 \%$ está por sobre el $90 \%$ de cumplimiento. En esta categoría, la media de la banca chilena supera largamente a la media neocelandesa $[14,15](87 \%$ y $63 \%$ respectivamente), lo que habla claramente que las funcionalidades relacionadas al ámbito transaccional de los servicios electrónicos bancarios chilenos para personas están mayormente introducidas en Chile.

En términos de heterogeneidad, la varianza de la banca nacional supera a NZ (172 contra 112 respectivamente), lo que da a entender que dentro de la realidad chilena los servicios bancarios están más disgregados respecto a la media antes mencionada, es decir, en Chile a pesar de que existe una mayor cantidad promedio de funcionalidades a las que acceder, el acceso real a ellas depende de la institución a la que se pertenezca.

Como se puede apreciar en la figura 8 en la banca nacional, en lo que respecta a facilidad de uso no es tan desarrollada,

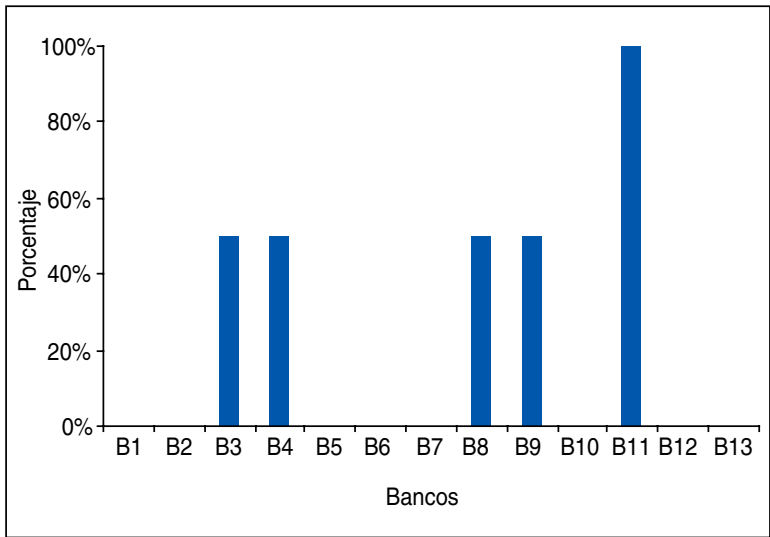

Figura 6. Desempeño de la banca chilena para la categoría estado legal.

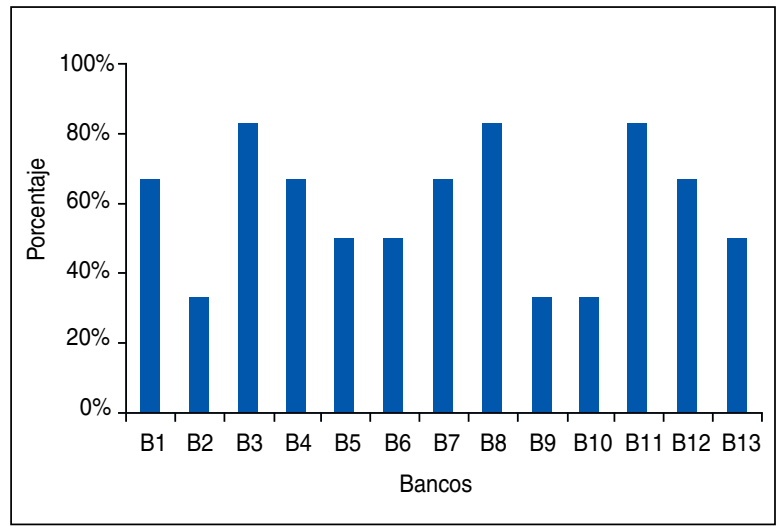

Figura 8. Desempeño de la banca chilena para la categoría facilidad de uso.

ya que solo el $23 \%$ de los bancos evaluados están en un $83 \%$ de los ítems considerados, igual porcentaje cumple con un 33\% de dichos atributos. En NZ esta categoría presenta una media más alta, es decir, en dicha nación los servicios son más fáciles de usar [14,15].

En la figura 9 se puede ver que en lo referente a términos estéticos y audio, la banca chilena es bastante homogénea, puesto que el $77 \%$ de los bancos cumple con el $67 \%$ de los ítems evaluados. Por otra parte, sólo 2 de los 13 bancos cumplen con el $100 \%$ de los ítems; mientras en NZ el $57 \%$ de las instituciones lo hace $[14,15]$.

Para el caso de la categoría desempeño, figura 10, el $54 \%$ de los bancos evaluados cumple con el $67 \%$ de los elementos considerados para medir el desempeño, y solo el $31 \%$ cumple con el $100 \%$ de los elementos, cabe destacar que 2 bancos (15\%) no cumplen con ninguno de los elementos para la medición del desempeño. En términos generales la banca neocelandesa se desenvuelve mejor con una media del $96 \%$ de los elementos evaluados $[14,15]$ versus un $67 \%$ para el caso nacional. 
Para concluir el análisis comparativo por categorías de ambas bancas a continuación se presentan los resultados generales de la evaluación de funcionalidades:

$\begin{array}{lcc} & \text { Chile } & \text { Nueva Zelanda } \\ \text { Media } & 71 \% & 74 \% \\ \text { Varianza } & 71 & 41\end{array}$

Según los resultados anteriores, la media de servicios electrónicos es levemente superior en NZ. Por otro lado, en términos de varianza, la banca nacional supera a NZ, lo que en definitiva comprueba que dentro de la realidad chilena los servicios bancarios están más disgregados respecto a la media antes mencionada, es decir, en Chile a pesar de que existe una cantidad promedio de funcionalidades similar a NZ, el acceso real a ellas depende de la institución a la que se pertenezca. Las categorías que influyen mayormente en lo anterior son: Estado Legal, Uso y Desempeño.

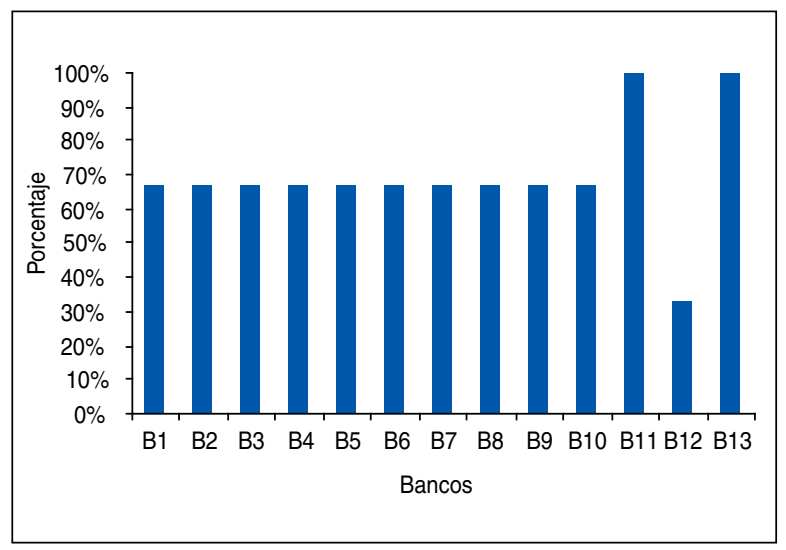

Figura 9. Desempeño de la banca chilena para la categoría efectos estéticos y audio.

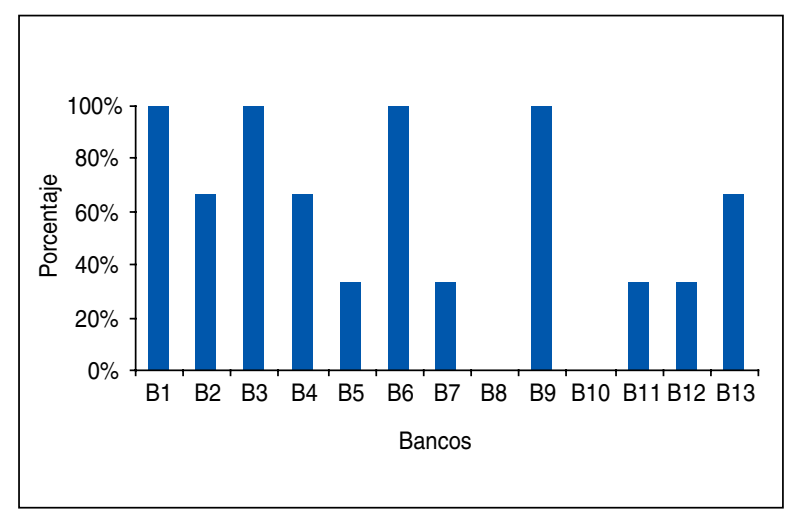

Figura 11. Desempeño de la banca chilena para la categoría promoción.
Los análisis para las categorías Promoción y Valor Agregado, que se presentan a continuación, no se comparan con la banca de NZ, debido a que estas categorías fueron introducidas adicionalmente en el estudio realizado en Chile.

En lo que se refiere a promoción, se tiene que el 31\% de los bancos cumple con la totalidad de los elementos evaluados (100\%), igual proporción solo cumple con el 33\% de los elementos, dos de los bancos no cumple con ninguno de los ítems señalados, esto se puede ver en la figura 11.

En lo que respecta a la categoría valor agregado, representado en la figura 12 , se tiene que el $38 \%$ de los bancos evaluados (5) cumple con el $100 \%$ de los elementos evaluados, el $31 \%$ de la banca cumple con el $67 \%$ de los elementos, $8 \%$ con el $33 \%$, y el $23 \%$ con ninguno de los elementos.

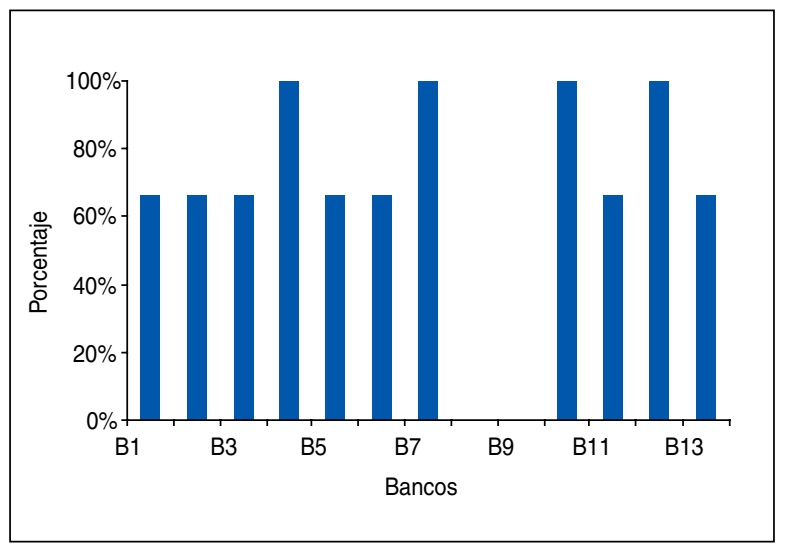

Figura 10. Desempeño de la banca chilena para la categoría desempeño.

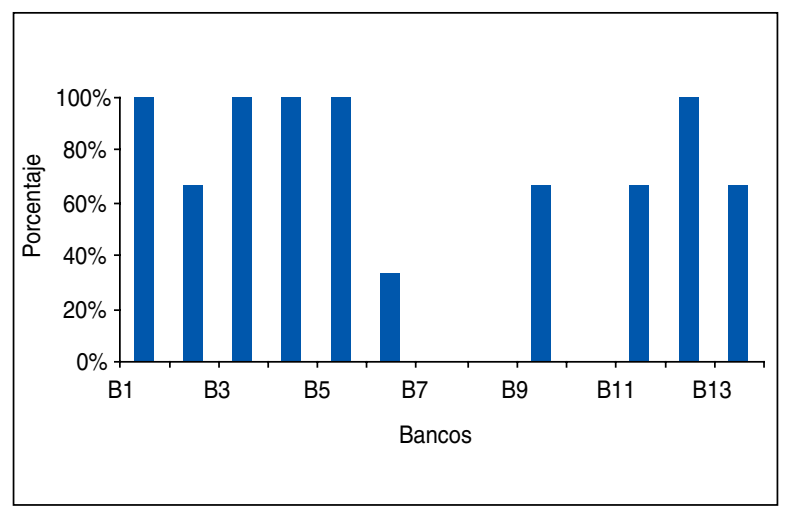

Figura 12. Desempeño de la banca chilena para la categoría valor agregado. 


\section{PERCEPCIÓN DE LOS CLIENTES}

Para el estudio también se aplicó una encuesta tendiente a indagar lo más profundamente posible en las características de los clientes, en sus preferencias, gustos, opiniones, etc. Con esta información fue posible obtener valiosas conclusiones para la banca nacional contrastando la percepción de los consumidores con la evaluación de desempeño de la banca nacional.

Para la encuesta se optó por aplicar en nuestro país una adaptación de la encuesta desarrollada en 2001 por los académicos John Paynter y Winnie Chung [14, 15] de la Universidad de Auckland, Nueva Zelanda, quienes facilitaron el material para la realización de este estudio en Chile. Para la encuesta se utilizó un muestreo no probabilístico que en este caso fue por conveniencia y por cuotas.

Para determinar el tamaño muestral se consideró el supuesto de varianza máxima y donde, además, se aceptó un error del $6 \%$ como máximo; se trabajó, además, con un $95 \%$ de nivel de confianza, lo que otorga mayor seguridad. Por tanto, el tamaño muestral quedó en 251 personas. En estudios similares a éste llevados a cabo en Malasia [13] y Nueva Zelanda [14, 15], los tamaños muestrales utilizados fueron 300 y 200 respectivamente.

\section{RESULTADOS GENERALES DE LA ENCUESTA}

Dado que en este estudio se pretendía obtener principalmente las percepciones de los usuarios de la banca por Internet, la muestra arrojó un $68,8 \%$ (174) de encuestados que son usuarios de la banca por Internet contra un 31,2\% (77) de aquellos que no lo son. Estos datos son de un orden similar al nivel de penetración (62\%) publicado por la Superintendencia de Bancos e Instituciones Financieras (SBIF).

Dentro de los usuarios de los servicios bancarios a través de Internet del país, un 77,8\% (136) declaró hacer uso de la banca por Internet a través de su banco principal, mientras el 22,2\% (38) restante dijo estar registrado en otros servicios de la banca en línea aparte de su banco principal.

De los resultados de la encuesta, es posible desprender que alrededor de un $75 \%$ de los usuarios utilizan la banca por Internet con una frecuencia mínima de una vez a la semana, lo cual implicaría que tras él existe un nivel de satisfacción importante.

Respecto a la antigüedad de uso de los servicios de la banca por Internet, aproximadamente un 56\% de los usuarios recurren a ella hace más de un año, un $24 \%$ entre 6 y 12 meses y un $20 \%$ hace menos de 6 meses.

En cuanto a la búsqueda de información financiera en Internet un $69,3 \%$ declara que recurre a la red para acceder a ella, mientras que el 30,3\% restante no utiliza el canal para tales servicios. La información de tasas de interés, de préstamo y el tipo de cambio son las actividades más requeridas.

Considerando las visitas a páginas Web bancarias un $85,9 \%$ de los encuestados declaró haber visitado alguna, mientras el $14,1 \%$ nunca ha visitado una página Web bancaria chilena

Dentro de los usuarios, el uso de la banca por Internet se sitúa en la actualidad como el servicio más utilizado $(18,9 \%)$, seguido del cajero automático (17,4\%), la línea de crédito $(14,7 \%)$ y los servicios convencionales a través de la caja/mesón $(13,2 \%)$. Los demás servicios consultados recibieron los siguientes porcentajes: tarjeta de débito $(11,5)$, banca telefónica $(7,8)$, pago automático de cuentas $(6,8)$, pago de cuentas en línea $(6,4)$ y otros $(3,5)$

Por otra parte, dentro de los no usuarios de la banca por Internet predomina el uso de los servicios convencionales a través de la caja/mesón (28\%), seguido del cajero automático $(27,3 \%)$ y luego la línea de crédito $(14,7 \%)$.

Si se considera el total de los encuestados (usuarios y no usuarios) el nivel de uso de los servicios se distribuye de la siguiente forma: cajero automático $(19,2 \%)$, servicios convencionales a través de la caja/mesón $(15,9 \%)$, banca por Internet $(\mathbf{1 5 , 5 \% )}$, línea de crédito $(14,7 \%)$, tarjeta de débito $(11,4 \%)$, banca telefónica (7,9\%), pago automático de cuentas $(6,7 \%)$, pago de cuentas en línea $(5,2 \%)$, $(2,2 \%)$ y otros $(3,6 \%)$.

\section{USO DE LOS DISTINTOS SERVICIOS/ ACTIVIDADES BANCARIAS}

De los resultados de la encuesta se desprende que dentro de los usuarios de la banca en línea los servicios más usados son: consultas de saldo $(23,2 \%)$, consulta de cartolas de movimientos $(21,2 \%)$ y transferencias de fondos entre cuentas del mismo banco $(12,2 \%)$.

\section{Factores que inhiben el uso de la banca por Internet}

La tabla 2 muestra que en Chile el principal factor para no registrarse en la banca por Internet es "Poder hacer los trámites bancarios de otra forma", seguido por "No 
estar informado de los servicios de la banca por Internet ofrecidos por el banco" y "No haberlo intentado antes". En NZ el principal aspecto inhibidor es la "Inseguridad acerca de la seguridad de las transacciones" que se sitúa en el cuarto lugar en Chile con la misma media.

Considerando los aspectos menos importantes en la inhibición tanto en Chile como en NZ, de inmediato llama la atención la gran disparidad que presenta entre ambas naciones el aspecto "No estar informado de los servicios a través de Internet ofrecidos por el banco", el cual en Chile se sitúa en el segundo lugar como factor de inhibición, mientras en $\mathrm{NZ}$ en la posición doce de las trece razones evaluadas, lo cual podría interpretarse como causa de una menor difusión (marketing) del canal en Chile.

Observando la tabla 2 se desprende que en Chile los aspectos inhibidores son en general barreras de entrada más fuertes para el uso del servicio que en NZ, ya que presentan calificaciones más altas.

Tabla 2. Razones para no registrarse en la banca por Internet en Chile.

\begin{tabular}{|l|c|c|}
\hline \multicolumn{1}{|c|}{ Razón } & $\begin{array}{c}\text { Media } \\
\text { CL }\end{array}$ & $\begin{array}{c}\text { Media NZ } \\
{[\mathbf{1 4 , 1 5}]}\end{array}$ \\
\hline $\begin{array}{l}\text { Puedo hacer los trámites bancarios de } \\
\text { otra forma }\end{array}$ & 3,95 & 3,56 \\
\hline $\begin{array}{l}\text { No estoy informado de los servicios de } \\
\text { la banca por Internet de mi banco }\end{array}$ & 3,67 & 1,95 \\
\hline No lo he intentado antes & 3,66 & 3,51 \\
\hline $\begin{array}{l}\text { Dudas (Inseguridad) acerca de la } \\
\text { seguridad de las transacciones }\end{array}$ & 3,65 & 3,65 \\
\hline $\begin{array}{l}\text { No necesito acceso instantáneo a mis } \\
\text { cuentas las 24 horas }\end{array}$ & 3,64 & 3,42 \\
\hline $\begin{array}{l}\text { Prefiero hablar con alguien en persona } \\
\text { en la sucursal }\end{array}$ & 3,50 & 3,21 \\
\hline $\begin{array}{l}\text { Inseguridad acerca de cómo trabaja la } \\
\text { banca por Internet }\end{array}$ & 3,43 & 2,76 \\
\hline $\begin{array}{l}\text { Inseguridad acerca de qué tan positivo } \\
\text { es este servicio }\end{array}$ & 3,41 & 2,99 \\
\hline $\begin{array}{l}\text { la banca por Internet ofrece un número } \\
\text { limitado de servicios }\end{array}$ & 3,13 & 3,14 \\
\hline $\begin{array}{l}\text { No tengo acceso (o tengo acceso } \\
\text { limitado) a Internet }\end{array}$ & 3,00 & 1,57 \\
\hline $\begin{array}{l}\text { No pienso que la banca por Internet } \\
\text { sea más barata }\end{array}$ & 2,89 & 3,17 \\
\hline $\begin{array}{l}\text { La banca por Internet es complicada } \\
\text { de usar }\end{array}$ & 2,80 & 2,42 \\
\hline $\begin{array}{l}\text { Demasiado problemático registrarse } \\
\text { en la banca por Internet }\end{array}$ & 2,80 & 3,05 \\
\hline
\end{tabular}

En cuanto a la probabilidad de registro futuro en doce meses, los no usuarios declararon lo siguiente: muy improbable (17,9\%), improbable $(32,1 \%)$, probable $(48,2 \%)$ y muy probable $(1,8 \%)$. Lo cual indica que el $50 \%$ es probable que se registre a pesar de sus preocupaciones e inhibiciones, lo que muestra el alto potencial del servicio y permite inferir que con un trabajo en los aspectos inhibidores más importantes dicha tasa de probable registro podría aumentar.

\section{ANÁLISIS DE FACTORES PARA LOS ASPECTOS INHIBIDORES}

La tabla 3 muestra los resultados obtenidos luego de realizar un análisis de factores con rotación varimax.

Dicho análisis entregó los siguientes factores:

Factor 1: Seguridad-preferencia por servicios convencionales.

(36\% de la varianza total).

Factor 2: Dificultad.

( $12 \%$ de la varianza total).

Factor 3: Desconocimiento-desinformación. (11\% de la varianza total).

Factor 4: Dudas de los beneficios. (10\% de la varianza total).

\section{CARACTERÍSTICAS DE LOS USUARIOS DE LA BANCA POR INTERNET EN CHILE}

En la tabla 4 se aprecia que el registro o no de una persona para hacer uso de la banca por Internet está relacionado con la edad, el sexo y el uso de servicios a través de la caja/mesón. Muy cerca del límite de dependencia se encuentra el ser usuario de la banca telefónica (valor que sobrepasa levemente el nivel de significancia exigido Se consideró un valor $\alpha=0,05$ para la determinación). Por otra parte, se ve claramente que el estar registrado no depende del nivel educacional completo más alto, ingreso, estado civil y el uso de cajero automático. Los registrados en la banca por Internet se caracterizan principalmente por ser con mayor probabilidad hombres de entre 20 y 40 años que siguen utilizando los servicios convencionales caja/mesón aunque en un menor grado que la banca por Internet.

Por otra parte, es posible determinar, a partir de las relaciones, que personas de un determinado ingreso (siendo cuentacorrentistas), nivel educacional más alto, estado civil o usuarios de cajero automático no son necesariamente probables usuarios de la banca por Internet, ya que en estos casos la hipótesis nula de independencia entre las variables no fue rechazada. 
Tabla 3. Análisis de factores para los aspectos inhibidores.

\begin{tabular}{|c|c|c|c|c|c|}
\hline \multirow[t]{2}{*}{ Aspectos } & \multicolumn{4}{|c|}{$\begin{array}{c}\text { Cargas de los } \\
\text { factores }\end{array}$} & \multirow[t]{2}{*}{ Comunalidad } \\
\hline & 1 & 2 & 3 & 4 & \\
\hline $\begin{array}{l}\text { 1. No estoy } \\
\text { informado de los } \\
\text { servicios de la } \\
\text { banca por Internet } \\
\text { de mi banco }\end{array}$ & $-0,00$ & 0,10 & 0,70 & 0,04 & 0,508 \\
\hline $\begin{array}{l}\text { 2. No estoy seguro } \\
\text { acerca de qué } \\
\text { tan positivo es } \\
\text { este servicio en } \\
\text { comparación con } \\
\text { la forma en que } \\
\text { actualmente realizo } \\
\text { trámites }\end{array}$ & 0,22 & 0,53 & 0,42 & $-0,09$ & 0,511 \\
\hline $\begin{array}{l}\text { 3. Pienso que la } \\
\text { banca por Internet } \\
\text { es complicada de } \\
\text { usar }\end{array}$ & 0,28 & 0,73 & 0,02 & 0,22 & 0,655 \\
\hline $\begin{array}{l}\text { 4. Tengo dudas } \\
\text { acerca de la } \\
\text { seguridad de las } \\
\text { transacciones }\end{array}$ & 0,61 & 0,14 & 0,10 & 0,29 & 0,487 \\
\hline $\begin{array}{l}\text { 5. No pienso que la } \\
\text { banca por Internet } \\
\text { sea más barata }\end{array}$ & 0,11 & 0,35 & 0,02 & 0,49 & 0,373 \\
\hline $\begin{array}{l}\text { 6. Pienso que la } \\
\text { banca por Internet } \\
\text { ofrece un número } \\
\text { limitado de } \\
\text { servicios }\end{array}$ & 0,19 & 0,12 & 0,06 & 0,53 & 0,333 \\
\hline $\begin{array}{l}\text { 7. Puedo hacer los } \\
\text { trámites bancarios } \\
\text { de otra forma }\end{array}$ & 0,67 & 0,21 & 0,11 & 0,24 & 0,560 \\
\hline $\begin{array}{l}\text { 8. No necesito } \\
\text { acceso a mis } \\
\text { cuentas las } 24 \text { horas }\end{array}$ & 0,65 & 0,06 & 0,08 & 0,00 & 0,430 \\
\hline $\begin{array}{l}\text { 9. Prefiero hablar } \\
\text { con alguien en } \\
\text { persona }\end{array}$ & 0,78 & 0,32 & $-0,04$ & 0,18 & 0,738 \\
\hline $\begin{array}{l}\text { 10. No tengo acceso } \\
\text { (o tengo acceso } \\
\text { limitado) a Internet }\end{array}$ & 0,28 & 0,17 & 0,30 & 0,06 & 0,202 \\
\hline $\begin{array}{l}\text { 11. Parece } \\
\text { demasiado } \\
\text { problemático } \\
\text { registrarse la banca } \\
\text { por Internet }\end{array}$ & 0,16 & 0,73 & 0,12 & 0,23 & 0,631 \\
\hline $\begin{array}{l}\text { 12. No lo he } \\
\text { intentado antes }\end{array}$ & 0,24 & $-0,09$ & 0,37 & 0,33 & 0,312 \\
\hline $\begin{array}{l}\text { 13. Estoy inseguro } \\
\text { de cómo trabaja la } \\
\text { banca por Internet }\end{array}$ & 0,74 & 0,21 & 0,27 & 0,27 & 0,741 \\
\hline
\end{tabular}

Tabla 4. Relaciones de dependencia para la determinación de las características de los usuarios de la banca por Internet en base al test estadístico Chi-cuadrado de Pearson.

\begin{tabular}{|l|c|c|c|}
\hline \multicolumn{1}{|c|}{ Relaciones } & $\chi^{2}$ & Significancia & $\begin{array}{c}\text { Relación de } \\
\text { dependencia }\end{array}$ \\
\hline $\begin{array}{l}\text { Registro en la } \\
\text { banca por Internet } \\
\text { v/s edad }\end{array}$ & 9,783 & 0,010 & Sí \\
\hline $\begin{array}{l}\text { Registro en } \\
\text { la banca por } \\
\begin{array}{l}\text { Internet v/s nivel } \\
\text { educacional más } \\
\text { alto }\end{array}\end{array}$ & 2,226 & 0,161 & No \\
\hline $\begin{array}{l}\text { Registro en la } \\
\text { banca por Internet } \\
\text { v/s ingreso }\end{array}$ & 2,223 & 0,356 & No \\
\hline $\begin{array}{l}\text { Registro en la } \\
\text { banca por Internet } \\
\text { v/s sexo }\end{array}$ & 7,309 & 0,006 & Sí \\
\hline $\begin{array}{l}\text { Registro en la } \\
\text { banca por Internet } \\
\text { v/s estado civil }\end{array}$ & 2,536 & 0,252 & No \\
\hline $\begin{array}{l}\text { Registro en la } \\
\text { banca por Internet } \\
\text { v/s uso cajero } \\
\text { automático }\end{array}$ & 1,251 & 0,194 & No \\
\hline $\begin{array}{l}\text { Registro en la } \\
\text { banca por Internet } \\
\text { v/s uso banca } \\
\text { telefónica }\end{array}$ & 2,479 & 0,079 & No \\
\hline $\begin{array}{l}\text { Registro en la } \\
\text { banca por Internet } \\
\text { v/s servicios } \\
\text { caja/mesón }\end{array}$ & 4,916 & 0,019 & \\
\hline
\end{tabular}

\section{LA IMPORTANCIA DE LOS DISTINTOS ELEMENTOS}

Además de los resultados ya entregados en esta sección, tanto a los usuarios como no usuarios de la banca por Internet se les consultó acerca de qué tan importantes son/serían un conjunto de catorce aspectos. Para ello debían asignarle a cada uno una nota de 1 a 7 , en que 1 representaba la menor importancia y 7 la mayor. Los resultados de esta medición se pueden ver en la tabla 5.

Al comparar los resultados de la tabla 6 es posible apreciar que entre ambos países existe similitud en cuanto a la posición en que quedan ubicados la gran mayoría de los aspectos evaluados, lo que da a entender que entre ambas naciones los elementos en estudio tienen una importancia relativamente similar, sin embargo, los promedios asignados a cada elemento difieren. Esto 
trae consigo que la media chilena general $(6,04)$ supere a la media neocelandesa $(5,54)$, lo que significa que en Chile los aspectos considerados tienen un mayor peso, traduciéndose esto en una mayor responsabilidad para los bancos dado lo que los clientes esperarían según la importancia que le otorgan.

Tabla 5. La importancia de cada elemento.

\begin{tabular}{|l|c|c|}
\hline Elemento & $\begin{array}{c}\text { Media } \\
\text { CL }\end{array}$ & $\begin{array}{c}\text { Media NZ } \\
{[\mathbf{1 4 , 1 5}]}\end{array}$ \\
\hline Seguridad & 6,64 & 6,65 \\
\hline Proveer información actualizada & 6,55 & 6,33 \\
\hline Tiempo de respuesta & 6,41 & 6,08 \\
\hline $\begin{array}{l}\text { Disponer de servicios libres de problemas } \\
\text { técnicos }\end{array}$ & 6,36 & 6,21 \\
\hline $\begin{array}{l}\text { Facilidad de navegación en la página } \\
\text { del banco }\end{array}$ & 6,33 & 5,73 \\
\hline Tiempo de descarga & 6,28 & 5,83 \\
\hline Facilidad de uso de la banca por Internet & 6,25 & 5,76 \\
\hline Contar con información del cliente & 6,21 & 5,64 \\
\hline Contar con información de productos & 6,04 & 5,41 \\
\hline $\begin{array}{l}\text { Rango apropiado de servicios bancarios } \\
\text { en Internet }\end{array}$ & 5,94 & 5,47 \\
\hline Contar con información del banco & 5,85 & 5,47 \\
\hline Disponer de un servicio de demostración & 5,76 & NO \\
\hline Interfaces gráficas atractivas & 5,47 & 4,09 \\
\hline Uso de animaciones & 4,44 & 3,32 \\
\hline
\end{tabular}

\section{ANÁLISIS DE FACTORES PARA LA IMPORTANCIA DE LOS DISTINTOS ASPECTOS}

Se determinó que para lograr un entendimiento más global de la importancia de los distintos aspectos era necesario realizar un análisis de factores. La tabla 6 muestra los resultados obtenidos luego de la realización del análisis.

Según las más altas cargas (correlaciones) entre los factores y cada uno de los catorce elementos, fue posible determinar y denominar a los tres factores encontrados de la siguiente forma:

Factor 1: Desempeño (47\% de la varianza total)

Factor 2: Estética (13\% de la varianza total)

Factor 3: Información (10\% de la varianza total)

En términos del efecto que este análisis puede tener sobre la efectividad de los servicios que se entregan, es necesario mencionar que debido a que estos tres factores fueron obtenidos a partir de la importancia asignada a catorce elementos, las tres nuevas variables permiten un control más fácil de los catorce aspectos subyacentes, lo cual puede redundar en el mantenimiento o mejora del desempeño de aquellos elementos bien o mal calificados según su importancia.

Tabla 6. Análisis de factores para la importancia de cada elemento.

\begin{tabular}{|l|c|c|c|c|}
\hline \multicolumn{1}{|c|}{ Elemento } & \multicolumn{2}{|c|}{ Cargas de los factores } & \multirow{2}{*}{ Comunalidad } \\
\hline $\begin{array}{l}\text { Proveer información } \\
\text { actualizada }\end{array}$ & 0,668 & $-0,014$ & 0,393 & 0,601 \\
\hline $\begin{array}{l}\text { Contar con } \\
\text { información del } \\
\text { banco }\end{array}$ & 0,231 & 0,372 & 0,612 & 0,566 \\
\hline $\begin{array}{l}\text { Contar con } \\
\text { información de } \\
\text { productos }\end{array}$ & 0,208 & 0,131 & 0,750 & 0,623 \\
\hline $\begin{array}{l}\text { Contar con } \\
\text { información del } \\
\text { cliente }\end{array}$ & 0,446 & 0,187 & 0,487 & 0,471 \\
\hline Seguridad & 0,739 & $-0,006$ & 0,250 & 0,609 \\
\hline $\begin{array}{l}\text { Rango apropiado de } \\
\text { serv. bancarios en } \\
\text { Internet }\end{array}$ & 0,419 & 0,299 & 0,385 & 0,413 \\
\hline $\begin{array}{l}\text { Facilidad de uso de } \\
\text { la banca por Internet }\end{array}$ & 0,845 & 0,263 & 0,114 & 0,796 \\
\hline $\begin{array}{l}\text { Facilidad de } \\
\text { navegación en la } \\
\text { página del banco }\end{array}$ & 0,797 & 0,341 & 0,149 & 0,775 \\
\hline Tiempo de respuesta & 0,774 & 0,214 & 0,181 & 0,678 \\
\hline Tiempo de descarga & 0,521 & 0,391 & 0,224 & 0,475 \\
\hline $\begin{array}{l}\text { Disponer de } \\
\text { servicios sin } \\
\text { problemas técnicos }\end{array}$ & 0,674 & 0,145 & 0,241 & 0,534 \\
\hline $\begin{array}{l}\text { Interfaces gráficas } \\
\text { atractivas }\end{array}$ & 0,199 & 0,756 & 0,298 & 0,700 \\
\hline $\begin{array}{l}\text { Disponer de } \\
\text { un servicio de } \\
\text { demostración }\end{array}$ & 0,222 & 0,718 & 0,124 & 0,581 \\
\hline Uso de animaciones & 0,039 & 0,618 & 0,078 & 0,389 \\
\hline
\end{tabular}

\section{DESEMPEÑO DE LOS BANCOS CHILENOS SEGÚN LAS PERCEPCIONES DE LOS CLIENTES}

Como se comentó en el transcurso de esta sección, tanto los usuarios como no usuarios fueron consultados acerca de la importancia que otorgaban en una escala de 1 a 7 a los aspectos antes expuestos. Con este procedimiento fue posible obtener el "peso" de cada elemento, el cual se muestra en la tabla 7. 
El Desempeño Promedio representa el cometido medio de todos los bancos nacionales según la percepción de los clientes para el aspecto en cuestión; a partir de este dato se obtiene el Puntaje de Desempeño que es simplemente el porcentaje que representa cada aspecto respecto al máximo puntaje posible de obtener $(7,0)$. La Importancia Promedio es básicamente la nota media asignada por los encuestados según cada elemento, es decir, representa el peso que cada aspecto tiene para ellos según su propia asignación de importancia. De esto último se obtiene el Puntaje de Importancia que representa la importancia promedio en términos porcentuales, es decir, Importancia Promedio/Puntaje Máximo (7,0).

En la tabla 8 se puede ver que el elemento "Seguridad" a pesar de ser sindicado como el aspecto más importante queda relegado a un segundo lugar debido a que "Proveer información actualizada" lo supera en desempeño promedio y como consecuencia de esto en desempeño ponderado. Así el aspecto en que la banca por Internet chilena se desempeña mejor en términos reales es en proveer información actualizada.

De la tabla 8 es posible extraer que según la apreciación de los clientes el único aspecto en el cual la banca neocelandesa supera en su desempeño ponderado a la chilena es en "Proveer información actualizada"; mientras que en todos los demás la Internet banking chilena muestra un mejor desempeño. Sin embargo, es necesario agregar que considerando sólo los desempeños promedios, en general la banca neocelandesa supera a la chilena [14, 15], pero dado que los clientes nacionales evaluaron con mayor importancia los aspectos en cuestión, el desempeño ponderado chileno supera al de NZ.

\section{DETERMINACIÓN DE CORRELACIONES ENTRE LOS DISTINTOS RANKINGS ELABORADOS}

Durante el desarrollo de este estudio se elaboraron distintos rankings, a los cuales se les aplicaron distintos test estadísticos para determinar las relaciones existentes entre ellos. La tabla 9 muestra los coeficientes de correlación de rankings de Spearman para los distintos rankings elaborados y consultados.

En el primer caso la hipótesis nula es rechazada (significancia 0,02 menor que nivel alfa 0,05), lo que significa que en la banca nacional los rankings de evaluación de sitios Web y percepciones de los clientes están correlacionados, es decir, los consumidores perciben en general como mejores (peores) a aquellos bancos que en la evaluación de funcionalidades de cada sitio Web resultaron bien (mal) evaluados, lo cual habla muy bien de la banca chilena.

Tabla 7. Desempeño de la banca chilena según cada aspecto.

\begin{tabular}{|c|c|c|c|c|c|}
\hline Aspecto & 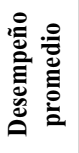 & 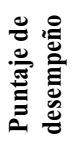 & 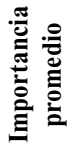 & 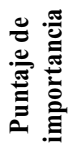 & 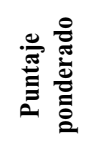 \\
\hline $\begin{array}{l}\text { Proveer información } \\
\text { actualizada }\end{array}$ & 6,09 & $87 \%$ & 6,55 & $94 \%$ & $81,4 \%$ \\
\hline Seguridad & 5,95 & $85 \%$ & 6,64 & $95 \%$ & $80,7 \%$ \\
\hline Tiempo de respuesta & 5,61 & $80 \%$ & 6,41 & $92 \%$ & $73,4 \%$ \\
\hline $\begin{array}{l}\text { Facilidad de } \\
\text { navegación en la } \\
\text { página del banco } \\
\end{array}$ & 5,64 & $81 \%$ & 6,33 & $90 \%$ & $72,8 \%$ \\
\hline $\begin{array}{l}\text { Facilidad de uso de } \\
\text { la banca por Internet }\end{array}$ & 5,69 & $81 \%$ & 6,25 & $89 \%$ & $72,5 \%$ \\
\hline $\begin{array}{l}\text { Proveer suficiente } \\
\text { información del } \\
\text { cliente }\end{array}$ & 5,61 & $80 \%$ & 6,21 & $89 \%$ & $71,1 \%$ \\
\hline Tiempo de descarga & 5,39 & $77 \%$ & 6,28 & $90 \%$ & $69,0 \%$ \\
\hline $\begin{array}{l}\text { Disponer de } \\
\text { servicios libres de } \\
\text { problemas técnicos }\end{array}$ & 5,27 & $75 \%$ & 6,36 & $91 \%$ & $68,5 \%$ \\
\hline $\begin{array}{l}\text { Proveer suficiente } \\
\text { información de } \\
\text { productos }\end{array}$ & 5,47 & $78 \%$ & 6,04 & $86 \%$ & $67,4 \%$ \\
\hline $\begin{array}{l}\text { Proveer suficiente } \\
\text { información del } \\
\text { banco }\end{array}$ & 5,41 & $77 \%$ & 5,85 & $84 \%$ & $64,6 \%$ \\
\hline $\begin{array}{l}\text { Rango apropiado de } \\
\text { servicios bancarios } \\
\text { en Internet }\end{array}$ & 5,29 & $76 \%$ & 5,94 & $85 \%$ & $64,2 \%$ \\
\hline $\begin{array}{l}\text { Disponer de } \\
\text { un servicio de } \\
\text { demostración } \\
\end{array}$ & 4,98 & $71 \%$ & 5,76 & $82 \%$ & $58,6 \%$ \\
\hline $\begin{array}{l}\text { Interfaces gráficas } \\
\text { atractivas }\end{array}$ & 5,15 & $74 \%$ & 5,47 & $78 \%$ & $57,5 \%$ \\
\hline Uso de animaciones & 4,68 & $67 \%$ & 4,44 & $63 \%$ & $42,5 \%$ \\
\hline
\end{tabular}

En el test realizado para determinar la correlación entre los rankings de participación de mercado global y participación de mercado Internet, la hipótesis nula es rechazada, por lo cual existe una relación directa entre el tamaño de un banco como institución y su tamaño en Internet. 
Tabla 8. Nota de desempeño ponderado para cada aspecto de la banca por Internet chilena.

\begin{tabular}{|l|c|c|}
\hline \multicolumn{1}{|c|}{ Aspecto } & $\begin{array}{c}\text { Nota } \\
\text { ponderada } \\
\text { CL }\end{array}$ & $\begin{array}{c}\text { Nota } \\
\text { ponderada } \\
\text { NZ }\end{array}$ \\
\hline $\begin{array}{l}\text { Proveer información } \\
\text { actualizada }\end{array}$ & 5,89 & 5,98 \\
\hline Seguridad & 5,84 & 5,62 \\
\hline Tiempo de respuesta & 5,40 & 5,02 \\
\hline $\begin{array}{l}\text { Facilidad de navegación en la } \\
\text { página del banco }\end{array}$ & 5,37 & 4,96 \\
\hline $\begin{array}{l}\text { Facilidad de uso de la banca } \\
\text { por Internet }\end{array}$ & 5,35 & 5,26 \\
\hline $\begin{array}{l}\text { Proveer suficiente } \\
\text { información del cliente }\end{array}$ & 5,27 & 4,96 \\
\hline Tiempo de descarga & 5,14 & 4,36 \\
\hline $\begin{array}{l}\text { Disponer de servicios libres } \\
\text { de problemas técnicos }\end{array}$ & 5,11 & 5,12 \\
\hline $\begin{array}{l}\text { Proveer suficiente } \\
\text { información de productos }\end{array}$ & 5,05 & 4,66 \\
\hline $\begin{array}{l}\text { Proveer suficiente } \\
\text { información del banco }\end{array}$ & 4,88 & 4,72 \\
\hline $\begin{array}{l}\text { Rango apropiado de servicios } \\
\text { bancarios en Internet }\end{array}$ & 4,85 & 4,66 \\
\hline $\begin{array}{l}\text { Disponer de un servicio de } \\
\text { demostración }\end{array}$ & 4,52 & NO \\
\hline Interfaces gráficas atractivas & 4,45 & 3,34 \\
\hline Uso de animaciones & 3,55 & 2,56 \\
\hline
\end{tabular}

Tabla 9. Coeficiente de correlación de ranking de Spearman para los distintos ranking obtenidos.

\begin{tabular}{|l|c|c|c|}
\hline \multicolumn{1}{|c|}{ Aspecto } & $\mathbf{r}_{\mathbf{s}}$ & Significancia & Correlación \\
\hline $\begin{array}{l}\text { Evaluación de los sitios } \\
\text { Web v/s Percepción de } \\
\text { los Clientes }\end{array}$ & 0,648 & 0,020 & Sí \\
\hline $\begin{array}{l}\text { Ranking de participación } \\
\text { de Mercado (Tamaño } \\
\text { Banco) v/s Evaluación de } \\
\text { los Sitios Web }\end{array}$ & 0,479 & 0,125 & No \\
\hline $\begin{array}{l}\text { Ranking de participación } \\
\text { de Mercado (Tamaño } \\
\text { Banco) v/s Percepciones } \\
\text { de los Clientes }\end{array}$ & 0,175 & 0,562 & No \\
\hline $\begin{array}{l}\text { Ranking de participación } \\
\text { de Mercado (Tamaño } \\
\text { Banco) v/s Ranking } \\
\text { participación de Mercado } \\
\text { Internet }\end{array}$ & 0,807 & 0,003 & Sí \\
\hline
\end{tabular}

\begin{tabular}{|l|c|c|c|}
\hline $\begin{array}{l}\text { Ranking de participación } \\
\text { de Mercado Internet v/s } \\
\text { Evaluación de sitios Web }\end{array}$ & 0,519 & 0,077 & No \\
\hline $\begin{array}{l}\text { Ranking de participación } \\
\text { de Mercado Internet } \\
\text { v/s Percepciones de los } \\
\text { Clientes }\end{array}$ & 0,308 & 0,331 & No \\
\hline
\end{tabular}

La tabla 10 muestra las posiciones que ocupan los bancos chilenos de acuerdo a la evaluación de sitios Web y a las percepciones de los consumidores.

Respecto a los coeficientes de correlación que muestran la relación entre el ranking de participación de mercado global (tamaño del banco) y los ranking de evaluación de sitios Web y percepciones de los clientes, en ambos casos la hipótesis nula no puede ser rechazada, lo que implica que el tamaño de un banco no tiene relación con la evaluación de los servicios que ofrecen como así tampoco con la percepción que los consumidores puedan tener del servicio según el tamaño del banco.

Tabla 10. Posiciones bancarias según evaluación de sitios web y percepciones de los clientes.

\begin{tabular}{|c|c|c|}
\hline Banco & $\begin{array}{c}\text { Posición según } \\
\text { evaluación } \\
\text { de sitios Web }\end{array}$ & $\begin{array}{c}\text { Posición según } \\
\text { percepciones de } \\
\text { los clientes }\end{array}$ \\
\hline B11 & 4 & 2 \\
\hline B4 & 1 & 4 \\
\hline B8 & 12 & 13 \\
\hline B13 & 5 & 1 \\
\hline B1 & 3 & 5 \\
\hline B9 & 9 & 12 \\
\hline B5 & 7 & 11 \\
\hline B10 & 12 & 10 \\
\hline B7 & 11 & 8 \\
\hline B2 & 9 & 6 \\
\hline B3 & 2 & 7 \\
\hline B6 & 7 & 3 \\
\hline B12 & 5 & 9 \\
\hline
\end{tabular}

\section{RELACIONES DE SATISFACCIÓN GENERAL}

Los usuarios de la banca por Internet fueron consultados acerca del éxito que tenían para finalizar sus trámites bancarios a través de Internet, cuyas respuestas hicieron saber que el nivel de éxito es relativamente alto, lo que habla bien de la banca por Internet nacional. Las respuestas de los clientes fueron las siguientes: Siempre $(31,2 \%)$, Casi siempre $(51,2 \%)$, A veces $(12,8 \%)$, Casi 
nunca $(2,4 \%)$ y Nunca $(2,4 \%)$. Estos datos se mantienen dentro de un orden similar a los publicados por el Centro de Economía Digital de la Cámara de Comercio de Santiago (CEDCCS) [7] y hablan de la alta efectividad y simplicidad de uso de los servicios, lo cual permite explicar la alta frecuencia con que los usuarios recurren a los servicios bancarios a través de Internet y también los altos niveles de satisfacción que muestran.

Tabla 11. Ranking final para la banca por Internet chilena.

\begin{tabular}{|c|c|c|}
\hline Banco & $\begin{array}{c}\text { Puntaje } \\
\text { promedio }\end{array}$ & $\begin{array}{c}\text { Posición según } \\
\text { ambas evaluaciones }\end{array}$ \\
\hline B4 & 2,5 & 1 \\
\hline B11 & 3 & 2 \\
\hline B13 & 3 & 2 \\
\hline B1 & 4 & 4 \\
\hline B3 & 4,5 & 5 \\
\hline B6 & 5 & 6 \\
\hline B12 & 7 & 7 \\
\hline B2 & 7,5 & 8 \\
\hline B5 & 9 & 9 \\
\hline B7 & 9,5 & 10 \\
\hline B9 & 10,5 & 11 \\
\hline B10 & 11 & 12 \\
\hline B8 & 12,5 & 13 \\
\hline
\end{tabular}

Respecto a cómo describen los usuarios el desempeño de su banco en la banca por Internet, un $0,8 \%$ declara calificarlo como pésimo, un 7,3\% como pobre, un 19,5\% como adecuado, un $61,8 \%$ como bueno y un $10,6 \%$ como excelente.

Considerando los resultados entregados por los usuarios acerca del nivel de satisfacción general, un 2,4\% de ellos declaró sentirse muy insatisfecho, un 5,7\% insatisfecho, un $12,2 \%$ ni satisfecho ni insatisfecho, un $69,1 \%$ satisfecho $\mathrm{y}$ un $10,6 \%$ muy satisfecho.

Ante la pregunta ¿Qué tan probable o improbable es que siga usando los servicios de la banca por Internet en los próximos doce meses?, el 3,3\% contestó muy improbable, el $8,1 \%$ improbable, el $33,3 \%$ probable y el $55,3 \%$ muy probable. Este resultado da entender la importancia del servicio y concuerda con el grado de satisfacción.

En vista de que la satisfacción general, tabla 12, depende de algunos elementos que pueden ser atribuibles al desempeño pasado, como son: el uso futuro y la frecuencia de uso, la satisfacción general no se relaciona con el tiempo que un cliente ha hecho uso de los servicios. Según los datos, implica que mientras mayor sea el tiempo que un cliente ha hecho uso de los servicios, más probable es que siga usándolos en el futuro, pero no hay que olvidar, de acuerdo a los resultados aquí expuestos, que no necesariamente su tiempo de uso implicará un mayor nivel de satisfacción.

Tabla 12. Relaciones de dependencia de la satisfacción general en base al test Chi-cuadrado de Pearson.

\begin{tabular}{|l|c|c|c|}
\hline \multicolumn{1}{|c|}{ Relaciones } & $\chi^{\mathbf{2}}$ & Significancia & $\begin{array}{c}\text { Relación de } \\
\text { dependencia }\end{array}$ \\
\hline $\begin{array}{l}\text { Satisfacción general } \\
\text { v/s uso futuro }\end{array}$ & 35,30 & 0,0000 & Sí \\
\hline $\begin{array}{l}\text { Satisfacción general } \\
\text { v/s tiempo de uso }\end{array}$ & 2,49 & 0,2815 & No \\
\hline $\begin{array}{l}\text { Satisfacción general } \\
\text { v/s frecuencia de uso }\end{array}$ & 7,12 & 0,0306 & Sí \\
\hline $\begin{array}{l}\text { Uso futuro v/s } \\
\text { tiempo de uso }\end{array}$ & 7,61 & 0,0064 & Sí \\
\hline
\end{tabular}

\section{CONCLUSIONES}

Considerando la información analizada para el desarrollo de este estudio, es posible concluir que la banca chilena muestra un alto grado de efectividad, ya que tanto en la evaluación de sitios Web como en las percepciones de los consumidores las instituciones fueron bien evaluadas en los distintos aspectos considerados.

De acuerdo al análisis comparativo de funcionalidades de ambas bancas, la media de servicios electrónicos es muy similar entre Chile y NZ. Sin embargo, la banca chilena muestra una varianza que supera a NZ, lo que significa que dentro de la realidad chilena los servicios bancarios están más disgregados respecto a la media antes mencionada, es decir, en Chile, a pesar de que existe una cantidad promedio de funcionalidades similar a NZ, el acceso real a ellas depende de la institución a la que se pertenezca. Las categorías que más influencia tienen en las diferencias de varianza comentadas son: Estado Legal, Uso y Desempeño.

Si bien es cierto en el contexto global Chile se desempeña de manera muy positiva en cuanto a las funcionalidades que ofrece, se debe poner atención a la categoría Estado Legal, en la cual se muestra la efectividad más baja de todos los aspectos considerados en este estudio. En este ámbito, los clientes necesitan una declaración explícita, fácil de entender y de simple acceso que les recuerde y explique todos los aspectos concernientes a la seguridad del servicio. 
La literatura sugiere que dentro de los servicios de la banca por Internet existen tres niveles de desarrollo: fundamentales, dinámicos e inteligentes [16]. De acuerdo a esto los servicios de la banca por Internet chilenos se ubican en la categoría más alta, presentando un estándar mundial en cuanto a la cantidad de servicios ofrecidos.

Analizando el sector bancario en general, es posible concluir que en lo que respecta a comercio electrónico y valor agregado, se trata de categorías que tienen una importancia estratégica, ya que son funcionalidades específicas dirigidas a un público minoritario y especial, siendo estas categorías las que amplían las diferencias entre el número de funcionalidades ofrecidas por las instituciones de mayor y menor desempeño global.

En lo referente a innovación, se concluye que el grado de efectividad de este elemento es bajo. A modo de sugerencia los bancos podrían introducir servicios especiales para discapacitados, relacionar en un mayor grado los servicios de la banca por Internet con el acceso a los servicios a través de telefonía móvil u ofrecer condiciones o beneficios especiales (de tasas de interés u otros) a quienes suscriban determinados servicios a través de esta vía.

Considerando las dos etapas de este estudio, es posible determinar que los servicios de la banca por Internet en Chile poseen un alto grado de efectividad, teniendo en general muy poco que envidiar a los sistemas bancarios electrónicos de otras naciones más desarrolladas como país y en el ámbito de las TI’s, como es el caso de Nueva Zelanda.

Los altos grados de satisfacción general, probabilidad de uso futuro, penetración y desempeño bancario avalan lo expuesto anteriormente. Además, es muy importante considerar la alta correlación existente entre las dos principales etapas de esta investigación, la cual introduce un nuevo aliciente a la alta calificación obtenida por la banca en línea chilena, ya que señala que el trabajo realizado por las instituciones es percibido de una forma bastante similar por los clientes.

También es necesario concluir acerca del alto potencial que posee la banca por Internet en Chile, lo cual queda de manifiesto con el $62 \%$ de penetración alcanzado a fines de 2004, lo que asegura que a fines de 2005 el nivel de penetración bordeará el 70\%, lo cual es incluso más alto que las proyecciones de estudios amparados por el Banco Mundial [10] para los países desarrollados en los años antes mencionados. Considerando lo anterior, las percepciones de los clientes y los importantes ahorros de costos que trae consigo la banca por Internet, es necesario que los bancos mejoren y amplíen constantemente sus servicios y productos para aumentar tanto la rentabilidad como la fidelidad de los consumidores que tienen un menor costo de cambio.

Principalmente dentro de las grandes instituciones se da una alta presión de mercado por introducir nuevos servicios, lo cual se manifiesta frente a la aparición de nuevas funcionalidades que son rápidamente imitadas por el mercado una vez lanzadas, afectando el desempeño innovativo de los servicios. De aquí se desprende que los bancos deben adoptar ya sea una estrategia ofensiva o defensiva para su presencia en la red.

\section{RECOMENDACIONES Y LIMITACIONES}

Para un estudio posterior sería muy interesante agregar a la metodología un factor de ponderación para las distintas categorías consideradas en la evaluación de sitios Web. Con esto se obtendría eventualmente un ranking distinto al de este estudio.

También hay que aclarar que los servicios de la banca por Internet están en constante cambio, lo cual implica que los resultados obtenidos pueden ir variando según el momento en que el estudio se lleve a cabo

Dado el bajo grado de retroalimentación que parecen mostrar los bancos con el cliente electrónico, sería importante dar a conocer esta falencia e introducir este método de control de manera constante.

\section{REFERENCIAS}

[1] D. Amor. "La (R) Evolución E-business". Editorial Prentice Hall. 2002.

[2] S. Davidson. "Internet Banking: Key Strategic and Tactical Issues for Community Bankers". Community Banker. Steven Community Banker. 2000 .

[3] C. Zinski. "Internet Banking: The Trade Name Trend". Banking \& Financial Services Policy. 2001. Fecha de consulta 30 de mayo de 2005. www.shiffhardin.com.

[4] J. Paynter, S. Satitkit. "Evaluating Usability of New Zealand E-tailing Sites". Department of Management Science and Information Systems School of Business. The University of Auckland, 2002. 
[5] A. Wright, D. Ralston. "The Lagging Development of Small Business Internet Banking in Australia". Journal of Small Business Management. 2002.

[6] S. Amenábar, C. Godoy. "Internet en la Industria Bancaria Chilena”. Facultad de Ciencias Económicas y Administrativas. Universidad Católica. 1999.

[7] Centro de Estudios de la Economía Digital. "La Economía Digital en Chile 2002”. Editorial Cámara de Comercio de Santiago. 2002.

[8] Centro de Estudios de la Economía Digital. "La Economía Digital en Chile 2001”. Editorial Cámara de Comercio de Santiago. 2001.

[9] World Internet Project, UC. "La Penetración de Internet en Chile está estancada en un 36 por ciento". 3 de agosto de 2005.

http://www.puc.cl/noticias/ficha/pub1492.html

[10] S. Claessens, T. Glaesnner, D. Klingebiel. "Electronic Finance, a New Approach to Financial Sector Development". The International Bank for Reconstruction and Development/The World Bank. Washington DC, USA. 2002.
[11] Superintendencia de Bancos e Instituciones Financieras. "Estadísticas Banca Internet". Diciembre 2004.

[12] D. Whiteley. "E-commerce: Strategy, Technologies and Applications". Editorial McGraw-Hill. 2000 .

[13] B. Suganthi. "Internet Banking Patronage: An Empirical Investigation of Malaysia”. 2000.

[14] W. Chung, J. Paynter. "An Empirical Investigation of Retail Internet Banking in New Zealand". Department of Management Science and Information Systems School of Business. The University of Auckland. 2002.

[15] W. Chung, J. Paynter. "An Evaluation of Internet Banking in New Zealand". Department of Management Science and Information Systems School of Business. The University of Auckland. 2002.

[16] C. Hamlet. "Community Banks Go Online”. ABA Banking Journal. 2000. 